\title{
Superior Cerebellopontine Cistern
}

National Cancer Institute

\section{Source}

National Cancer Institute. Superior Cerebellopontine Cistern. NCI Thesaurus. Code C33671.

The superior aspect of cerebellopontine cistern. 